\title{
E SE IVAN ILITCH FIZESSE ATIVIDADE FÍSICA?: REFLEXÕES SOBRE TORMENTOS MODERNOS
}

\author{
Ivan Marcelo Gomes
}

Doutor em Ciências Humanas pela UFSC e professor efetivo do Centro de Educação, Cultura e Artes da Universidade Estadual do Oeste do Paraná/Campus Cascavel.

\begin{abstract}
Resumo
Este estudo focaliza imperativos vinculados aos estilos de vida saudáveis e como estes se articulam com a sociedade contemporânea. Outros elementos destacados na análise foram as estratégias utilizadas pelo campo médico para tornar os indivíduos saudáveis. Buscou-se caracterizar tais estratégias em dois momentos: um primeiro descrito a partir de preocupações sociais com a ordem produtiva e um segundo conectado com a exacerbação dos riscos e da lógica de consumo que são potencializadores das formas de normatização social e responsabilização individual. As reflexões indicam que os conselhos médicos assumem o papel da razão e da moral em prol da vida saudável como atestam os combates às situações sociais caracterizadas como ambivalentes.
\end{abstract}

Palavras-chave: Risco - Consumo - Saúde.

\begin{abstract}
$\Lambda$ preocupação presente na elaboração deste texto consiste na reflexão sobre os imperativos vinculados aos estilos de vida saudáveis e como estes se articulam com a sociedade contemporânea, que cada vez mais invoca os riscos e o consumo ${ }^{1}$. Para iniciarmos tal reflexão não será apresentado, momentaneamente, um conceito, mas sim, um trecho literário.

Partiremos de um recorte da literatura, pois ele possibilita a visualização de uma problemática que nos confronta de uma maneira crescente na modernidade. Trata-se da recorrência a especialistas que possam contribuir para afugentar os perigos que rondam o corpo.

[...] Seu estado agravava-se pelo fato de ler livros de medicina e consultar vários médicos. O progresso de sua doença era tão mínimo que, ao comparar um dia com o outro, seria capaz de enganar-se, tão sutil era a diferença. Mas quando consultava os médicos tinha a impressão de estar piorando rapidamente, assustadoramente, a cada dia. Ainda assim, ele continuava consultando médicos.
\end{abstract}

1 Vale aqui a ressalva de que existe na área da Educação Física um intenso debate sobre as propostas que enfatizam a busca por estilos de vida saudáveis. Em termos ilustrativos, podemos citar a série de discussões organizadas por Bagrichevsky, Estevão e Palma presentes nos livros intitulados A saúde em debate na Educação Física volume 1 (2003), volume 2 (2006) e volume 3 (2007). Neste artigo, optamos por privilegiar um diálogo com a literatura sociológica, tendo em vista ser essa a fonte de muitos argumentos apresentados na produção acadêmica da Educação Física referente à temática em questão. 
Naquele mês foi consultar outra celebridade. Essa celebridade disse exatamente o mesmo que a primeira, sendo que ele elaborou as perguntas de modo diferente e a entrevista com essa celebridade apenas fez redobrar nele as dúvidas e os temores. Depois, um amigo de um amigo seu, um médico muito bom, deu outro diagnóstico para sua doença e, embora previsse que ele acabaria por se curar, suas perguntas e hipóteses confundiram-no ainda mais e aumentaram seu ceticismo. Um homeopata fez ainda um diagnóstico diferente e deu-lhe um remédio que ele tomou escondido por uma semana, mas, no final, não tendo sentido alívio algum e tendo perdido a confiança tanto nos remédios anteriores quanto nesse novo tratamento, acabou ficando ainda mais desanimado do que antes. Um dia, uma conhecida sua mencionou uma cura através de imagens milagrosas. Ivan Ilitch flagrou-se ouvindo atentamente e começando a acreditar na história como algo concreto. Este incidente assustou-o. 'A minha cabeça terá degenerado a esse ponto?', perguntava-se. 'Todas essas bobagens, esse lixo...!' Não devo me deixar impressionar, mas sim escolher um médico e seguir seriamente o tratamento que ele me der. É isso que eu vou fazer. Está decidido. Não vou mais pensar nisso, só seguir o tratamento até o verão e então veremos. De agora em diante nada de vacilações!' Isso tudo era fácil de dizer, mas impossível de colocar em prática [...] (TOLSTOI, 2006, p. 51-2).

Não pretendemos fazer uma análise literária, mas, a partir do recorte acima, estabelecer conexões com aspectos contemporâneos em virtude das possibilidades aventadas pela citação. Embora este trecho, extraído da obra A morte de Ivan Ilitch, de Leon Tolstoi, retrate o último quarto do século XIX, ele permite - em nosso entendimento - alçar vôos, mesmo que panorâmicos, sobre o presente.

Desta maneira, aspectos como a presença e os conselhos médicos especializados e legitimados pelo saber científico, os conflitos e os dilemas perante tais conselhos e intervenções, bem como a responsabilidade individual frente a estes dilemas abarcados pelas escolhas, transmitem uma sensação a nós, leitores desta obra, de algo comum, que nos afeta ainda hoje. Mas algo mudou em relação a este quadro? O tormento de Ivan Ilitch poderia ser pensado e vivenciado atualmente? Entendemos que sim, só que com nuances que refletem as mudanças vivenciadas na modernidade. Estas mudanças envolvem radicalizações de aspectos presentes na modernidade do século XIX, bem como mudanças de ênfase entre os "períodos" modernos.

Um outro recurso ilustrativo servirá para pensarmos as questões apontadas anteriormente e indicar uma das preocupações presentes no discurso contemporâneo dos estilos de vida saudáveis. Desta maneira, utilizaremos neste momento uma cena vivenciada por um indivíduo comum. Só que agora, não mais Ivan Ilitch, mas seu homônimo, o autor deste texto. Trata-se assim de um deslocamento de uma cena literária para um aspecto, digamos, do cotidiano. A cena (o fato) ocorreu há poucos anos quando, ao consultar um médico acompanhado de minha filha - na época com cinco anos -, desenrolou-se esta breve situaçãoº .

- Olá! O que está ocorrendo? - disse o médico.

- Tenho me sentido cansado, exausto. Também noto que tenho engordado...

- Fez os exames? (estes exames haviam sido solicitados por outro médico que me atendeu na semana anterior).

2 Logicamente, em virtude de ter sido um fato cotidiano e não um aspecto vivenciado em um campo de pesquisa, as palavras apresentadas não são totalmente fiéis ao acontecimento, mas a estrutura do diálogo permanece coerente e, principalmente, a prescrição. 
- Sim.

- Pelos exames você está bem, constatou o médico. E logo em seguida fez a seguinte indagação: Você faz atividade física?

- Muito pouco.

Neste momento ele olhou para minha filha e disse: esta é sua filha?

- Sim.

- Veja bem, preste atenção. Ou você caminha assiduamente ou talvez você não brincará mais com sua filha. A escolha é sua.

Encerrou-se a consulta e fui embora assustado e "convencido" da minha culpa.

Essa cena, ocorrida na sala de um hospital, retrata a rapidez das consultas médicas que parecem ser um fato aparentemente corriqueiro na atualidade. Para Martins (2003), ela contribui para a insatisfação com a biomedicina ocidental ${ }^{3}$, e também nos parece, como hipótese, que tal rapidez está vinculada a um repertório prévio estipulado pelo especialista (o médico), permitindo a utilização de jargões que se enquadram nos mais diferentes quadros apresentados pelos sujeitos submetidos a este breve "interrogatório". Além desta questão, outra emerge como aspecto fundamental para as pretensões a serem desenvolvidas neste texto: os conselhos vinculados ao estilo de vida saudável. A modelação do indivíduo saudável requer um combate insuflado pelos especialistas e um empenho do indivíduo em questão. Desta forma, o sedentarismo, a escassez de atividades físicas, tornou-se um alvo certeiro e de "fácil resolução": a necessidade de ser ativo. Esta recomendação apresenta uma "fórmula mágica" (a atividade física) que é evocada para diversos sintomas e que se torna um aspecto mensurável de uma "estética saudável" ${ }^{4}$. Retornaremos a esta consulta (digo, a esta discussão) posteriormente.

\section{A reverência dos sujeitos frente às celebridades médicas}

A insistência de Ivan Ilitch em visitar as celebridades (médicas) aponta para a importância da legitimação científica no enfrentamento dos perigos e adversidades presentes no mundo moderno. A medicina e seus especialistas, como representantes do saber científico de cunho anátomo-fisiológico, forneciam uma certa garantia de solução racional para os infortúnios enfrentados pelos sujeitos. Uma garantia de volta à normalidade. Para Canguilhem (2006), tal normalidade médica se confunde com o conceito de freqüência, como atesta a proposição de Quêtelet sobre o "homem

3 O autor comenta o aumento de reclamações dos usuários sobre o sistema médico, principalmente, em relação à corrente dominante, denominada pelo autor como "medicina tecnoutilitarista". A rapidez das consultas é apenas um dos efeitos presentes na crítica do autor. Segundo ele: "Na tradição biocartesiana, tal separação [médico e paciente] se fazia em nome da eficácia científica. Na versão bioutilitarista, essa separação é feita em nome da eficácia econômica (mais pacientes atendidos em menor tempo). Esses fatos concorrem para o enfraquecimento da medicina dominante como prática social de interesse público, embora seu sucesso econômico seja indiscutível” (MARTINS, 2003, p. 183).

4 Sobre a indicação da atividade física como "remédio" para diferentes situações e condições sociais, conferir o texto de Lovisolo (2002). 
médio”. Nesta perspectiva, o conceito de média e o conceito de normal se fundem e, mais do que isso, misturam fato (freqüência) e valor (dever ser).

Mas, mais do que as visitas e a busca por estes especialistas científicos, nos interessa a forma com que o campo médico participou de estratégias para tornar os indivíduos saudáveis. Assim, a cena muda de foco. A visita é "retribuída”.

Buscaremos caracterizar essas estratégias modernas em dois momentos: em um primeiro, descreveremos tais estratégias a partir das preocupações sociais com a ordem produtiva que propunha a identificação de problemas (sujeitos deficientes) e que a partir de intervenções, principalmente estatais, torná-los-iam eficientes para o desempenho de funções e de convivência social. Num segundo, tais estratégias se conectam com a exacerbação dos riscos e da lógica do consumo entrelaçadas com a noção de fator de risco que potencializa as formas de normatização social e, ao mesmo tempo, aumenta a responsabilização dos sujeitos perante suas ações.

As estratégias modernas do primeiro período têm nas propostas de Morel, psiquiatra francês do século XIX, aspectos bastante ilustrativos. Ele propunha táticas preventivas para vigiar e corrigir populações consideradas de risco a partir da verificação de freqüências de enfermidades mentais e outras anomalias em camadas mais desfavorecidas socialmente (CASTEL, 1986, p. 224). Desta maneira, Morel elaborou duas formas de intervenção: a profilaxia defensiva e a profilaxia preservadora. A primeira caracterizava-se pelo internamento em instituições disciplinares. A segunda caracterizava-se dentro de uma lógica de um tratamento moral generalizado. A extensão das propostas de Morel não se tornou viável, principalmente, em virtude das limitações técnicas presentes no período, mas elas se articularam com as tentativas que se seguiram no transcorrer do século XX. A necessidade de intervenções (principalmente do Estado) em determinados indivíduos localizados vinculava tais estratégias dentro do modelo panóptico ${ }^{5}$, que, por sua vez, se conectava com a ordem produtiva presente neste período.

É o próprio Castel (1981) quem fornece informações a este respeito. Para ele, a modernidade apresentou um modelo, por ele denominado "paradigma da assistência completa" ${ }^{\text {, }}$, vinculado a uma ordem produtiva, com uma lógica administrativa-burocrática, com pretensões objetivistas e que focava a deficiência. A preocupação central destas políticas estava na reinserção dos sujeitos ao mundo do trabalho. Este tipo de estratégia também apresentava outras características como a identificação do perigo em determinados sujeitos (uma peculiaridade imanente ao sujeito) e as situações de co-presença (como, por exemplo, as relações face-aface entre médico e paciente) balizadas pelo modelo panóptico (CASTEL, 1986). Tais características implicavam em uma forma de vigilância próxima, que acompanhava os sujeitos identificados com uma determinada deficiência que podia ou poderia impossibilitá-los no exercício das tarefas exigidas em uma sociedade que enfatizava a produção.

5 Para maior aprofundamento sobre o modelo panóptico, conferir Foucault (1996).

6 Embora a análise de Castel privilegie aspectos de estratégias na psiquiatria francesa, sua argumentação permite esclarecimentos em torno do nosso objetivo. 
Algumas nuances colaboraram na implantação de novas estratégias no decorrer do século XX, mais incisivamente ao final deste período. A ampliação das possibilidades tecnológicas contribuiu para a superação das estratégias apontadas anteriormente, principalmente no que se refere aos altos custos causados pelo aparato de vigilância panóptica.

Outro aspecto destas mudanças é apontado por Castel (1981). Ele argumenta que cada vez mais os especialistas da área médica estão implicados em uma gestão burocrática que os distancia da assistência e os envolve em diagnósticos. Estes diagnósticos se caracterizam pela avaliação da distância em relação à norma, sendo esta baseada em modelos sociais dominantes, mas que também se caracterizam por serem mutáveis. Para o autor, esta transição na função exercida por estes especialistas indicam um distanciamento de um modelo disciplinar que aproximava os profissionais dos alvos identificados. Desde então, a função dos especialistas se caracteriza mais fortemente como um instrumento na gestão de populações.

Rabinow (1999), baseando-se em Castel (1981), aborda outro aspecto desta transição: as transformações recentes do conceito de risco. Para ele:

O livro de Castel [A gestão dos riscos] é uma interrogação sobre a sociedade pós-disciplinar, que ele caracteriza por: (1) uma mutação de tecnologias sociais que minimiza a intervenção terapêutica direta, enfatizando, ao contrário, um gerenciamento administrativo preventivo de populações de risco; (2) a promoção do trabalho de cada um sobre si próprio de uma maneira contínua, a fim de produzir um sujeito eficiente e adaptável. [...]. (RABINOW, 1999, p. 144).

Como salienta Rabinow (1999), a ênfase destas estratégias de prevenção passa a focar "fatores de risco" despersonalizados ao invés dos riscos encarnados pelos sujeitos modernos. Castel (1986) complementa esta análise ao mostrar a dissolução do indivíduo concreto que é substituído pelos fatores de risco. Assim, objetiva-se se antecipar aos perigos, tendo em vista que os riscos combatidos podem se tornar comportamentos indesejáveis.

\section{Novas estratégias preventivas: os desafios individuais frente aos novos riscos contemporâneos (o tormento de ivan ilitch revisitado)}

O sujeito com suas escolhas e sua história é visto no discurso das novas estratégias preventivas não como um sujeito, mas como fragmentos probabilísticos transformados em fatores de risco. Com estas novas estratégias identificamos uma vigilância potencializada tecnologicamente que não isenta o aparato estatal de funções, mesmo que compartilhadas, em diversos casos, com a iniciativa privada. Articulado a isto é que Rabinow (1999, p. 145) argumenta que “[...] a prevenção é a vigilância, não do indivíduo, mas sim de prováveis ocorrências de doenças, anomalias, comportamentos desviantes a serem minimizados, e de comportamentos saudáveis a serem maximizados [...]”. Esses fatores de risco estipulados pelos especialistas com seus diagnósticos não são causados, em sua grande maioria, pelos sujeitos. Mas os sujeitos contemporâneos vivenciam o enfrentamento dos riscos como sendo de sua inteira responsabilidade. Isto gera uma insegurança, uma sensação "real" de vulnerabilidade que está vinculada ao declínio do Estado-Nação (no que se refere às garantias que 
ele proporcionava, ou buscava proporcionar) com o avanço neoliberal e as constantes ameaças produzidas pelo desenvolvimento tecnológico moderno (CASTEL, 2004). Trata-se de uma dupla insegurança.

Esta dupla insegurança é vivenciada de forma distinta pelos sujeitos na modernidade tardia. ${ }^{7}$ Embora os riscos sejam generalizados e espalhem-se nos mais diferentes espaços sociais, a maneira que eles afetam as pessoas é sentida em níveis acentuadamente diferenciados, como observado nas discussões de Mary Douglas sobre as relações entre riscos e minorias sociais (DOUGLAS, 1990, p. 13-4). Tal insegurança em dobro também apresenta suas ramificações na área da saúde. Atualmente, as estratégias na área da saúde não priorizam a correção de deficiências para a reintegração de setores populacionais ao mundo do trabalho, mas trata de assinalar destinos sociais diferentes aos indivíduos em função de sua capacidade para assumir as exigências de competitividade e rentabilidade (CASTEL, 1986, p. 241). Ainda em relação a estas assimetrias, verificamos que "tudo parece indicar que é mais simples normalizar condutas do que transformar condições perversas de existência" (CAPONI, 2003, p. 64).

A insegurança gerada pelos novos riscos apresenta-se em um horizonte de suplício perpétuo tendo em vista as características radicalizadas da modernidade a que estamos sujeitos na atualidade atrelada à lógica do consumo. A proliferação de sistemas peritos $^{8}$, o desenvolvimento tecnológico e a criação de necessidades para o deleite do consumidor potencializam a exacerbação dos riscos. Os riscos, ao mesmo tempo em que são fabricados, produzem inesperados perigos (GIDDENS, 1991). Tal aspecto está articulado com o sentido negativo que a noção de risco carrega na atualidade. Um sujeito conectado a determinado fator de risco tem sobre si as conseqüências negativas advindas deste elemento (DOUGLAS, 1990, p. 3). Ainda em relação a esta questão, Mitjavila (2002, p. 134) salienta que "o risco possui a virtualidade de oferecer, segundo a expressão de Mary Douglas, 'termos seculares para reescrever as sagradas escrituras'[...]".

Os riscos e os perigos gerados na modernidade tardia tornam-se uma responsabilidade individual perante a necessidade de ter que optar em função das novas mercadorias disponibilizadas para a prevenção de uma vida saudável. Os riscos tornam-se privatizados. Mas ao mesmo tempo não existe nenhuma garantia de que estas mesmas mercadorias serão no futuro, ou mesmo no presente (em função dos conflitos de especialistas e de racionalidades que configuram o cotidiano), percebidas como um risco ou como uma solução para a saúde. O que está colocado é a necessidade de ter que escolher, de ter que optar, de ter que defender o corpo. As escolhas tornam-se uma espécie de imperativo. Ou, em outras palavras, “ a modernidade cria, então, uma situação na qual selecionar e escolher representam verdadeiros imperativos socioculturais: os indi-

7 Para Giddens (1991, p.13): "Em vez de estarmos entrando num período de pós-modernidade, estamos alcançando um período em que as conseqüências da modernidade estão se tornando mais radicalizadas e universalizadas do que antes".

8 Giddens (1991, p.35) define da seguinte forma esse conceito: "Por sistemas peritos quero me referir a sistemas de excelência técnica ou competência profissional que organizam grandes áreas dos ambientes material e social em que vivemos hoje". 
víduos são convocados a recolher e articular os fragmentos de um mundo dilacerado do ponto de vista da significação subjetiva" (MITJAVILA, 2002, p. 132).

Este imperativo da escolha potencializa a insegurança vivenciada e a busca atônita por segurança. Desta forma, a prevenção aos riscos que podem tornar mais lânguido o corpo impregna os mais distintos espaços e ações cotidianas. A crença na eliminação de um risco alavancada a cada nova mercadoria depositada nas "prateleiras sociais" impulsiona os desejos de pureza e de felicidade em torno de um estilo de vida saudável.

Tais formas de controle e poder sobre a vida impulsionam alguns paradoxos atuais como a crescente disponibilização de informações sobre como obter um corpo saudável, mas que implica também em uma normalização do que seja tal corpo. $\mathrm{O}$ crescente número de especialistas e conselheiros da saúde saturam os diferentes espaços de informação e consumo. A ciência ainda fornece legitimidade às informações, mas agora ela pode ser divulgada não apenas pelos seus executores, como outrora representava a classe médica, para lembrarmos das celebridades de Ivan Ilitch. Digamos, como hipótese, de que atualmente os conselheiros que disponibilizam informações para a gestão individual dos riscos estão amplamente diversificados, não só entre os especialistas, como na utilização de artistas, atletas e até pessoas comuns ("gente como a gente", como ressaltam algumas propagandas).

Esta vastidão de especialistas e conselheiros privados, mesmo que oferecendo informações diferenciadas e conflituosas, reforçam a atribuição de responsabilidades aos indivíduos contemporâneos. Não só reforçam, como se constituem, como diz Bauman (1999), numa das fontes de angústia e incerteza do mundo contemporâneo. Porém, alguns discursos conectam estes diferentes apelos como percebemos amplamente na aceitação e profusão em torno dos estilos de vida saudáveis. Tais modelos parecem se constituir em um padrão de boa conduta. Mas, vale ressaltar que este padrão insiste na responsabilidade individual pelos riscos, mesmo que estes não possam ser controlados. Como lembra Mitjavila (2002):

[...] a individualização dos riscos supõe o desenvolvimento de técnicas para incitar, orientar, informar e controlar os indivíduos e as famílias a respeito das chances de ocorrência de acontecimentos indesejáveis. É bom que se lembre da importância que assume a idéia de estilo de vida, como locus privilegiado para a construção das trajetórias biográficas na modernidade tardia. Nesse sentido, em nome dos riscos, os árbitros da vida social podem justificar intervenções dirigidas a vigiar, orientar, controlar, julgar e, ainda, punir os indivíduos e os setores de população que não conseguem construir - ou que opõem resistência à construção de - 'estilos de vida saudáveis ou corretos' [...] (MITJAVILA, 2002, p. 139).

Esta preocupação também é compartilhada por Caponi (2003) ao referir-se à suprema valorização do bem-estar, como encontramos na conceituação de saúde da Organização Mundial da Saúde (OMS), e que pode "naturalizar" os fins de estratégias de controle e de exclusão. Ou em outros termos, o que escapa à norma/valor deve ser controlado e/ou extirpado. Para a autora:

A partir do momento em que se afirma o 'bem-estar' como valor - físico, psíquico e social -, reconhece-se como pertencente ao âmbito da saúde tudo aquilo que, em uma sociedade e em um momento histórico preciso, nós qualificamos de modo positivo - aquilo que produz ou que deveria produzir uma sensação de bem-estar, aquilo que se inscreve no espaço da normalidade: 
a laboriosidade, a convivência social, a vida familiar, o controle dos excessos [...]. (CAPONI, 2003, p. 67).

Entendemos que estes discursos e estratégias "saudáveis", por serem extremamente difundidos nas relações cotidianas, exercem uma pressão ainda maior sobre os indivíduos contemporâneos ${ }^{9}$. Assim, em virtude das assimetrias sociais, aspectos como a marginalização, a culpabilização, a estigmatização e a moralização não podem ser desconsiderados nas reflexões sobre a presente modernidade. $\mathrm{O}$ incentivo da "boa conduta", da "conduta correta", das "condutas saudáveis", se caracteriza como uma forma de enfrentamento individual dos fatores de risco e das anormalidades sociais (LUPTON, 1999; DOUGLAS, 1990). Desta maneira, sob a bandeira da redução do risco criam-se condenações morais e de competência destes indivíduos que saem da média da normalidade, como salientado por Douglas (1992 apud LUPTON, 1999, p. 46).

\section{Retorno ao consultório... Ou considerações finais}

Embora tenhamos argumentado sobre a crescente mediação técnica vinculada à responsabilização individual e que pode configurar um quadro de "isolamento" do indivíduo na construção do seu estilo de vida saudável, não podemos desconsiderar que a clínica ainda desempenha um papel importante neste processo. Como lembra Rabinow (1999, p. 148) "[...] continuam a existir uma multiplicação e uma imbricação complexa de racionalidades [...] práticas pós-disciplinares irão coexistir com tecnologias disciplinares [...]".

Os tormentos de Ivan Ilitch poderão ser revisitados agora sob o "pano de fundo" da consulta de seu homônimo. Conforme descrevemos na primeira parte deste texto, a consulta se caracterizou por alguns elementos: a rapidez, o jargão e o conselho para uma vida saudável (ativa).

A rapidez da consulta se conecta com o ambiente técnico e especializado vivenciado pela clínica e que se corporifica, ou seja, de uma forma não mediada, na relação entre os médicos especialistas e os pacientes. Ao mesmo tempo, ilustra a velocidade exigida pelas relações de consumo e que se alastram como forma de ação em diferentes espaços institucionais (MARTINS, 2003, p. 117).

O jargão, entendido como uma espécie de gíria profissional, está representado na identificação de indícios de fatores de risco: aumento de peso, inatividade. As perguntas e as "respostas esperadas" percorrem um script, como algo pré-definido. As mesmas perguntas que possivelmente se seguirão das mesmas recomendações diferentemente do indivíduo (paciente) postado a sua frente. Como lembra Castel (1986; 1981), atualmente, para ser suspeito basta apresentar algumas particularidades

9 Isto não significa que grupos considerados “anormais" (fora dos padrões) sejam esquecidos pelas estratégias tecnomercadológicas contemporâneas. Existem produtos especializados oferecidos pelo mercado para se ajustar aos interesses destes grupos. Como exemplo, podemos citar o mercado para obesos. Segundo reportagem publicada na Folha de São Paulo, os "produtos específicos para público acima do peso movimentam US\$ 117 bi, ante US\$ 33 bi na indústria de emagrecimento" nos EUA (GALVÃO, 2006, P. B8). Assim, a sociedade do risco e do consumo não dispensa estes indivíduos, pelo contrário, estes se ajustam às distintas possibilidades de construção dos estilos de vida. 
definidas pelos especialistas da política-preventiva, ou seja, fatores de risco. Embora os exames indicassem um "padrão de normalidade" o roteiro deveria prosseguir. O jargão é planificado, mas ajustável. A “confissão” de que estava acima do peso constituía um suspeito em potencial. Sendo ainda suspeito, o conselheiro poderia intervir para salvar o réu conscientizando-o através de "apelos" racionais (e morais).

O suspeito ainda não é o criminoso, assim como a margem pode não estar poluída. Mas em ambos os casos, a necessidade de vigilância deve ser redobrada pela insegurança que ela denota. Os esforços devem ser exaustivos para corrigir o que ainda é curável. Da mesma maneira, o sobrepeso torna-se um alvo identificável e corrigível, desde que o indivíduo "enquadrado" nesta categoria faça "o que deve ser feito"... se responsabilize por uma conduta ativa.

Assim, os conselhos médicos assumem o papel da razão (e da moral) na batalha em prol da vida saudável. A razão tenta combater a incerteza, mesmo que ela se baseie em cálculos probabilísticos como em determinadas teorias do risco nas sociedades modernas (ZINN, 2006). É por isso que as margens são perigosas (DOUGLAS 1992 apud LUPTON, 1999, p. 41), pois elas remetem a ambivalência de determinados fenômenos. Neste sentido, entendemos que a categoria do "sobrepeso" se enquadra nesta argumentação, visto que os indivíduos com sobrepeso são o foco mais acentuado dos discursos dos estilos de vida saudáveis. Eles devem ser vigiados e controlados, eles devem se vigiar e se controlar, pois ainda não cometeram o "pecado mortal": a obesidade. Para utilizar uma terminologia de Douglas (1992 LUPTON, 1999, p. 43), eles ainda não estão poluídos ${ }^{10}$.

Por fim, talvez, as vacilações e a impossibilidade de colocar em prática as recomendações médicas sejam os tormentos de Ivan Ilitch que mais se acentuem nos tempos atuais de riscos e de consumo exacerbado. A recorrente disponibilização de novos produtos e de novos e conflituosos conhecimentos, mesmo que conectados com a busca "ativa" da saúde, contribui para uma sensação sempre renovada de estar em débito consigo mesmo. $\mathrm{O}$ indivíduo com sobrepeso, responsabilizado e culpabilizado antecipadamente por não se esforçar como deveria, deve se locomover por entre uma série de especialistas aos quais tenha acesso e que lançam uma série de recomendações, transitórias e não necessariamente articuladas, para que esteja munido para a batalha. A munição parece excessiva - ou não oferecida adequadamente -, pois como lamentam os promotores de campanhas educativas para um estilo de vida saudável, tais indivíduos "equivocados" teimam em não seguir as instruções (como o autor deste texto, que não retornou para uma nova avaliação médica).

\title{
What if ivan ilitch did physical activities? Reflections on modern worries
}

\begin{abstract}
This study focuses on the imposition of healthy lifestyles and how these are articulated in contemporary society. Other elements highlighted in the analysis were the strategies doctors use to help individuals become healthy. Such strategies were characterized in two stances: the first one was written based on social preoccupations with the productive order, and the second one was connected with the increase
\end{abstract}

10 Vale lembrar que as idéias sobre poluição contribuem para reforçar pressões e regras sociais e estão associadas com códigos morais. Para maior esclarecimento conferir as análises de Lupton (1999, p. 42-3) sobre Mary Douglas. 
of risks and consumer logic which reinforce social norms and individual responsibilities. The reflections produced in this study indicate that medical advice take the role of both reason and moral in promoting a healthy life as can be demonstrated in the fights against social situations which are characterized as ambivalent.

Keywords: Risk- Consumerism - Health

\section{¿Y si ivan ilitch hiciera actividad física?: reflexiones sobre tormentos modernos}

\section{Resumen}

Enfoca imperativos vinculados a los estilos de vida saludables y cómo estos se articulan con la sociedad contemporánea. Otros elementos subrayados en el análisis fueron las estrategias empleadas en el ámbito médico para que los individuos se volvieran saludables. Se buscó caracterizar tales estrategias en dos momentos: un primer descrito desde las preocupaciones sociales con el orden productivo, y uno segundo conectado a la exacerbación de los riesgos y de la lógica del consumo, que son potenciadores de las formas de normas sociales y responsabilización individual. Las reflexiones indican que los consejos médicos asumen el papel de la razón y de la moral en pro de la vida saludable, como atestiguan los combates a las situaciones sociales caracterizadas como ambivalentes.

Palabras-clave: Riesgo - Consumo - Salud

\section{Referências}

BAGRICHEVSKY, M.; ESTEVÃO, A.; PALMA, A. (org.). A saúde em debate na Educação Física. Blumenau: Edibes, 2003.. . A saúde em debate na Educação Física - 2. Blumenau: Nova Letra, 2006. . A saúde em debate na Educaşão Física - 3. Ilhéus: Editus, 2007. . Modernidade e ambivalência. Rio de Janeiro: Jorge Zahar, 1999.

CANGUILHEM, G. O normal e o patológico. 6. ed. rev. Rio de Janeiro: Forense Universitária, 2006.

CAPONI, S. A saúde como abertura ao risco. In: CZERESNIA, D. (Org.). Promoção da saúde: conceitos, reflexões, tendências. Rio de Janeiro: Ed. Fiocruz, 2003. p. $55-77$.

CASTEL, R. La gestion preventiva. In: La gestion de los riesgos. Barcelona: Ed. Anagrama, 1981.p. 121-162.

. De la peligrosidad al riesgo. In: WRIGHT MILLS, C. et al. Materiales de sociologia critica. Madrid: Ediciones de la piqueta, 1986. p. 219-243.

. La inseguridad social: qué es estar protegido? 1. ed. Buenos Aires: Manantial, 2004.

DOUGLAS, M. Risk as a forensic resource. Daedalus. v. 119, n. 4, p. 01-16. 1990.

FOUCAULT, M. Vigiar e punir: nascimento da prisão. 13. ed. Petrópolis, RJ: Vozes, 1996.

GALVÃO, V. Q. Mercado para obeso gira um Chile nos EUA. In: Folha de São Paulo, São Paulo, 10 set. 2006. p. B8. 
GIDDENS, A. As conseqüências da modernidade. São Paulo: Unesp, 1991.

LOVISOLO, H. Atividade física e saúde: uma agenda sociológica de pesquisa. In: SIMÕES, R. e MOREIRA, W. W. (Org.). Esporte como fator de qualidade de vida. Piracicaba, SP: Unimep, 2002.

LUPTON, D. Risk and culture. In: . Risk. London: Routledge, 1999. p. 36-57.

MARTINS, P. H. Contra a desumanização da medicina: crítica sociológica das práticas médicas modernas. Petrópolis, RJ: Vozes, 2003.

MITJAVILA, M. O risco como recurso para a arbitragem social. In: Tempo Social Revista de Sociologia. São Paulo: USP, v. 14, n. 2, p. 129-145. out. 2002.

RABINOW, P. Artificialidade e iluminismo: da sociobiologia à biossociabilidade. In: . Antropologia da razão. Rio de Janeiro: Relume Dumará, 1999. p. 135-157.

TOLSTOI, L. A morte de Ivan Ilitch. Porto Alegre: L\&PM, 2006.

ZINN, J. O. Recent developments in sociology of risk and uncertainty. In: Forum: Qualitative Social Research. [On-line journal], v. 7, n. 1, art. 30, jan. 2006. Disponível em: http://www.qualitative-research.net/fqs-texte/1-06/06-1-30-e.htm. Acesso em: 23 out. 2006.

Recebido em: 01 de outubro de 2008

Revisado em: 01 de dezembro de 2008

Aprovado em: 03 de dezembro de 2008

Endereço para correspondência

ivanmgomes@hotmail.com. 